\title{
Paying for the pills
}

\section{How much does it really cost to put a new drug on the market?}

\section{The \$800 Million Pill: The Truth Behind the Cost of New Drugs \\ by Merrill Goozner \\ University of California Press: 2004. 297 pp. $\$ 24.95, £ 16.95$}

\section{John E. Calfee}

The $\$ 800$ Million Pill is open to trenchant criticism of some of its most basic points, but anyone who reads it will find some wonderful material. Merrill Goozner is a member of a small but influential group of journalists who, by training or diligence, have learned enough science and medicine to bridge the gap between science and policy without making fools of themselves. They perform a valuable service, not least because they can write well. Here Goozner effortlessly pulls the reader through some extremely complicated topics.

The title refers to a much cited and debated paper by Joseph DiMasi, Ronald Hansen and Henry Grabowski (J. Health Econ. 22, 151-185; 2003). Based on extensive but proprietary industry data, this study concluded that, on average, each drug introduced into the market from 1990 to 2001 involved total costs of US\$802 million. This figure takes into account the opportunity costs of capital and the costs of the numerous failures that litter the path of drug development.

Relying mainly on non-scholarly critics such as Public Citizen (a lobby group in Washington DC founded by Ralph Nader) and the Global Alliance for TB Drug Development, Goozner argues that DiMasi and colleagues grossly overstated the true costs of developing useful drugs. He accepts instead the Global Alliance's estimate that discovering and developing a new tuberculosis drug would cost only US\$115-240 million. Essentially, Goozner argues that the editors and reviewers of the Journal of Health Economics overlooked some basic methodological flaws in the paper. His argument is unpersuasive, though, partly because it defies sound economic reasoning on opportunity costs. It also ignores important limitations in the Global Alliance's study of developing a hypothetical drug for a single condition (tuberculosis) and using relatively small clinical trial sizes, non-market cost data and highly conjectural failure rates.

But $90 \%$ of this book is about other matters. Goozner pursues two main themes and many lesser ones. First, he claims that partly because of industry obfuscation, the world little appreciates the crucial role in the creation of new drugs played by research funded by non-industry sources, such as the US National Institutes of Health (NIH). His case

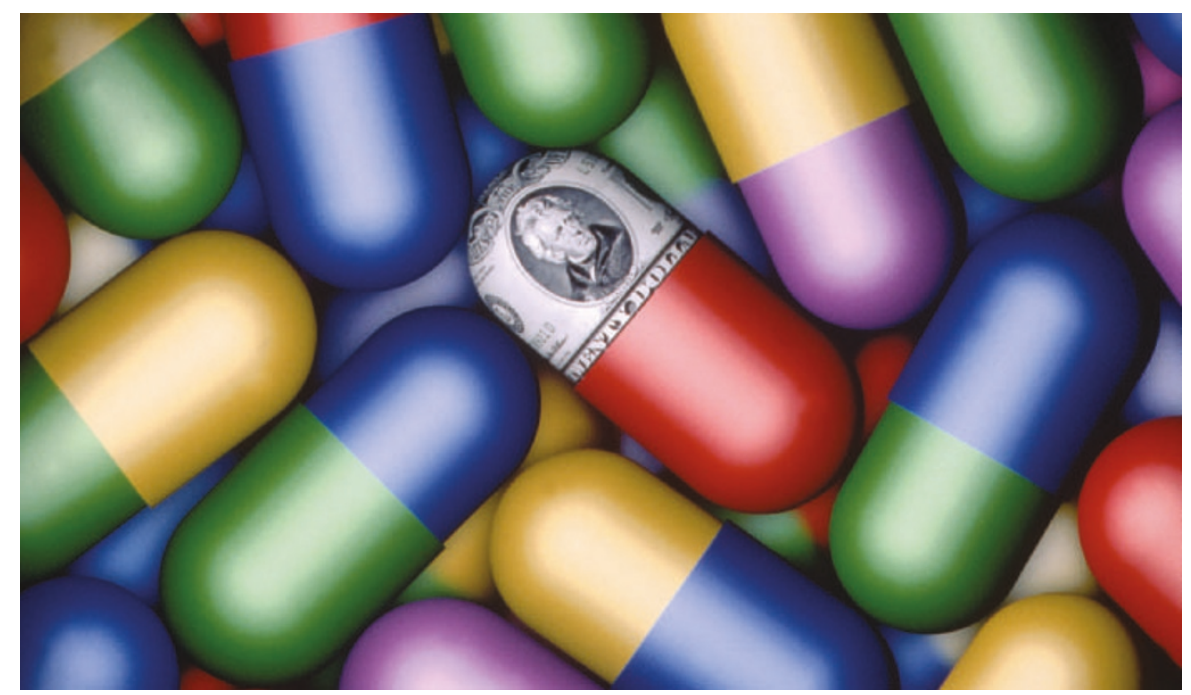

Strong medicine: pharmaceutical companies take a huge gamble when they develop a drug.

studies focus on HIV/AIDS (roughly onethird of the book), cancer and the biotechnology drugs erythropoietin and imatinib mesylate (Gleevec).

The details here are fascinating and many of his points are well delivered. But they fail to carry his wider argument: that the NIH and other non-industry sources typically complete the most difficult part of developing essential drugs and then turn them over to a few private firms to market them at immense profit. This argument is hard to square with the book's own repeated examples of the NIH's difficulties in overcoming the "reluctance" of individual firms to pursue the costly clinical trials needed to move a promising drug towards approval by the US Food and Drug Administration (FDA). This reluctance is understandable. The supply of promising molecules discovered with $\mathrm{NIH}$ money is very large. Anyone spending their own money will be very selective in deciding which of these is worth an investment of tens of millions of dollars to find out whether it is the rare success rather than the latest addition to the long list of costly failures.

This is where the economics gets ahead of Goozner, despite his formidable dedication and skills. A crucial point is not just the uncertainties of drug development, but the fact that, in the private sector, firms have to eat their mistakes. When Merck saw no fewer than four new drugs fail in phase 3 trials in 2003, the costs were borne by Merck stockholders and employees; there was no prospect of Merck covering those losses by simply raising the price of its existing drugs.

Goozner's other broad theme is that much of the industry's research and development is wasted in the pursuit of 'me-too' drugs that deliver easy profits but little medical benefit. Like most critics of follow-on drugs, Goozner does not offer a list of the unnecessary drugs that account for half of industry revenues. As recently pointed out by Thomas Lee (New Engl. J. Med. 350, 211-212; 2004), follow-on drugs typically cater for patients who are poorly served by existing drugs, and provide a strong dose of price competition. Economists have documented the potency of these market forces.

Goozner's recommendations reflect his major themes. Eschewing government controls over prices or profits (mainly, it seems, for political reasons), he seeks better information - of the most expensive kind. He wants more publicly funded clinical trials comparing new and old drugs. More importantly, he wants the FDA's new drug approval standards to require comparative clinical trials, but this would greatly increase costs without yielding comparable benefits. The FDA has repeatedly pointed out that comparison trials have to be very large to achieve the statistical power necessary to reveal genuine therapeutic differences. If the FDA requires such trials, they will probably show that the typical new drug helps at least some patients more than existing therapies, and that it still meets the FDA's standard for a safe and effective treatment. This approach is more likely to increase the costs of drug development than streamline the system. John E. Calfee is a resident scholar at the American Enterprise Institute, 1150 17th Street, NW, Washington DC 20036, USA.

John E. Calfee's employer receives financial contributions from individuals, foundations and corporations, including pharmaceutical firms. Some of his research received partial funding from the pharmaceutical industry. 